\title{
Stimulation of Somatostatin Expression in Developing Ciliary Ganglion Neurons by Cells of the Choroid Layer
}

\author{
James N. Coulombe and Rae Nishi \\ Department of Cell Biology and Anatomy, Oregon Health Sciences University, Portland, Oregon 97201
}

An important component of neuronal development is the matching of neurotransmitter expression with the appropriate target cell. We have examined how peptide transmitter expression is controlled in a simple model system, the avian ciliary ganglion (CG). This parasympathetic ganglion contains 2 distinct types of neurons: choroid neurons, which project to vasculature in the eye's choroid layer and use somatostatin as a co-transmitter with $\mathrm{ACh}$, and ciliary neurons, which innervate the ciliary body and iris and use $\mathrm{ACh}$ but no known peptide co-transmitter. We have found that the earliest developmental stage in which neurons with somatostatinlike immunoreactivity (SOM-IR) are consistently found in vivo is stage 30 (embryonic day 6.5), a time shortly after the extension of neurites to targets in the eye's choroid layer. In cell culture, CG neurons expressed SOM-IR in coculture with choroid cells, but not when cultured with striated muscle myotubes or with ganglion non-neuronal cells. No significant differences in neuronal survival or in ChAT activity were observed under these different co-culture conditions, which suggests that somatostatin expression is independently regulated. The stimulation of somatostatin expression was also specific in that other neuropeptides commonly found in autonomic neurons [neuropeptide $Y$ (NPY), substance P (SP), vasoactive intestinal polypeptide (VIP)] were not induced in the presence of choroid cells. The ability to stimulate SOM-IR was not contact dependent because a macromolecule of $\geq 10 \mathrm{kDa}$ in choroid-conditioned medium (ChCM) was found to stimulate somatostatin expression in a dosage-dependent fashion. The somatostatinstimulating activity induced SOM-IR in more than $90 \%$ of CG neurons, as well as in retrogradely labeled ciliary neurons, which would not normally express SOM-IR. Thus, the expression of somatostatin in cultured $\mathrm{CG}$ neurons is regulated by a macromolecule produced by cells in the choroid layer, a target normally innervated in vivo by CG neurons expressing somatostatin.

\footnotetext{
Received July 23, 1990; revised Oct. 2, 1990; accepted Oct. 5, 1990.

We thank T. Holbert and B. Boucher for their technical assistance and M. G. Coulombe and Drs. S. Matsumoto and F. Eckenstein for helpful comments. This work was supported by the Amyotrophic Lateral Sclerosis Association (R.N.), the American Heart Association, Oregon Affliate (R.N., J.N.C.), NIH Grant NS25767 to R.N., and NRSA Fellowship EY06178 to J.N.C.

Correspondence should be addressed to Rae Nishi, Department of Cell Biology and Anatomy, Oregon Health Sciences University, 3181 Southwest Sam Jackson Park Road, Portland, OR 97201.
}

Copyright (C) 1991 Society for Neuroscience $0270-6474 / 91 / 110553-10 \$ 03.00 / 0$
The formation of a functional nervous system requires the establishment of a vast number of specific connections. An essential property of this connectivity is that neurons express the appropriate neurotransmitter for their target of innervation. Little is known about the mechanisms by which this specificity is achieved. One plausible mechanism is that target cells or other aspects of the environment surrounding nerve terminals are able to regulate neurotransmitter expression in the neurons. A number of studies indicate that neurotransmitter expression is not fixed and can be altercd by cnvironmental influcnces even after a specific phenotype has been expressed (reviewed in Landis, 1990; see also Coulombe and Bronner-Fraser, 1986; Potter et al., 1986). For example, during development of the neonatal rat, a subpopulation of sympathetic neurons switches its neurotransmitter phenotype from adrenergic to cholinergic after contacting its targets (Yodlowski et al., 1984; Leblanc and Landis, 1986; Schotzinger and Landis, 1988). A similar adreneregicto-cholinergic change in neurotransmitter expression can also be induced in vitro in response to a glycoprotein purified from medium conditioned by heart cells (Fukada, 1985; see also Yamamori et al., 1989).

In addition to the small-molecule neurotransmitters such as $\mathrm{ACh}$ and catecholamines, many neurons employ peptide neurotransmitters. Within the PNS, the pattern of neuropeptide expression appears to be tightly correlated with target innervation (Lundberg et al., 1982; Leblanc and Landis, 1988; Macrae et al., 1986). This correlation has led to the speculation that the target cells specify the type of neuropeptide expressed by the innervating neuron. Although neuropeptide expression can be altered by experimental manipulations in a variety of neuronal systems (Mudge, 1981; Kessler, 1986; Black et al., 1987; McMahon and Gibson, 1987; Stevens and Landis, 1990), targetderived influences that specifically affect neuropeptide expression have been difficult to discern. Recently, some progress has been made, in that at least 3 distinct factors in heart-cell-conditioned medium have been identified that differ in their ability to induce neuropeptide expression in rat sympathetic neurons (Nawa and Patterson, 1990).

Our studies have focused upon regulation of transmitter phenotype in the developing chicken ciliary ganglion (CG). Previous studies of $\mathrm{CG}$ neurons have emphasized the role of tissue interactions in the control of neuronal survival and neurotransmitter expression. In vivo, developmental cell death of CG neurons is controlled by the availability of targets in the eye (Landmesser and Pilar, 1974; Pilar et al., 1980), and developmental increases in ChAT activity coincide with innervation of the eye (Chiappinelli et al., 1976; Coulombe and Bronner-Fraser, 1990). In cell culture, more than $90 \%$ of the CG neurons 
destined to die in vivo can be rescued by co-culture with myotubes or by soluble factors found in conditioned medium or cmbryo cxtract (Nishi and Berg, 1979). Recently, several related factors that support $\mathrm{CG}$ neuron survival have been purified from sciatic nerves and sequenced (Lin et al., 1989; Stöckli et al., 1989; Eckenstein et al., 1990). In addition, factors that mediate specific increases in ChAT activity of CG neurons have been identified (Nishi and Berg, 1979, 1981; Tuttle et al., 1980).

In this study, we have examined expression of the neuropeptide somatostatin in the chicken CG. In birds, the CG contains 2 distinct populations of neurons: ciliary neurons, which innervate the striated muscle of the iris and ciliary body, and choroid neurons, which innervate vascular smooth muscle in the choroid layer of the eye (Marwitt et al., 1971). Both types of neurons utilize $\mathrm{ACh}$ as a small-molecule neurotransmitter (Johnson and Pilar, 1980; Epstein et al., 1988). Recently, Epstein et al. (1988) established that a subset of neurons in the chick $\mathrm{CG}$ contains the neuropeptide somatostatin. The somatostatincontaining ncurons have smaller cell bodies, appear to contain less ChAT immunoreactivity, and lack caplike preganglionic synapses. Because these are characteristics of choroid neurons, these observations suggest that it is the choroid neurons that express somatostatin. Moreover, fibers with somatostatinlike immunoreactivity (SOM-IR) are found within the choroid layer of the eye, but not within the iris or ciliary body (Epstein et al., 1988; Gray et al., 1989, 1990). Within the choroid layer, somatostatin functions as a neuromodulatory agent inhibiting the release of ACh (Gray et al., 1989, 1990). Because both ciliary and choroid neurons share a common neural crest origin (Narayanan and Narayanan, 1978) and develop within the same ganglionic environment, we were interested in determining what factors regulated the differential expression of somatostatin in the ciliary ganglion.

\section{Materials and Methods}

Immunocytochemistry. Ciliary ganglia were removed from staged embryos (Hamburger and Hamilton, 1951), fixed in Zamboni's fixative ( $4 \%$ paraformaldehyde, $15 \%$ picric acid in $0.1 \mathrm{M}$ sodium phosphate buffer, $\mathrm{pH}$ 7.2), washed, infiltrated with sucrose, embedded in Tissue Tek, rapidly frozen, and sectioned at $5 \mu \mathrm{m}$ on a Leitz cryostat. Sections were dried onto gelatin-coated microscope slides and processed as described below.

Cultures processed for immunocytochemistry were washed with modified Puck's saline ( $124 \mathrm{~mm} \mathrm{NaCl}, 5 \mathrm{~mm} \mathrm{KCl}, 20 \mathrm{~mm}$ sodium phosphate, $\mathrm{pH}$ 7.3), fixed in Zamboni's fixative, and stored in modified Puck's saline at $4^{\circ} \mathrm{C}$.

Cultures or sections were preincubated in a blocking buffer $(0.5 \mathrm{M}$ $\mathrm{NaCl}$ in $0.1 \mathrm{~m}$ sodium phosphate, $\mathrm{pH} 7.2$, containing $5 \%$ chicken serum, $5 \%$ horse serum, $0.1 \%$ Triton- $X$, and $0.1 \%$ sodium azide) and reacted overnight with rabbit anti-somatostatin antiserum (INC Star Corp.) diluted 1:500 in the blocking buffer. The sections were washed and treated with $1 \% \mathrm{H}_{2} \mathrm{O}_{2}$ in $30 \%$ ethanol in $0.1 \mathrm{M}$ Tris $(\mathrm{pH}, 7.3)$ to destroy endogenous peroxidases. Binding of the primary antibodies was made visible by a double peroxidase-antiperoxidase method (PAP; Vacca et al., 1980; Ordronneau et al., 1981). Sections were incubated with a goat anti-rabbit antiserum (diluted 1:40 in blocking buffer lacking azide), followed by a peroxidase antiperoxidase enzymc-antibody complex (diluted 1:80 in blocking buffer lacking azide; Sternberger-Meyer Immunocytochemicals Inc.). The last 2 steps were repeated, followed by a reaction with $0.015 \% \mathrm{H}_{2} \mathrm{O}_{2}$ and $0.5 \%$ diaminobenzidine (DAB) in phosphate-buffered saline (PBS; $0.15 \mathrm{M} \mathrm{NaCl}, 0.01$ M sodium phosphate, pH 7.2). Controls included substitution of primary antiserum with normal rabbit serum and preabsorption of the anti-somatostatin primary antiserum with synthetic somatostatin. Dilute anti-somatostatin antiserum was incubated overnight at $4^{\circ} \mathrm{C}$ with $0.5 \mu \mathrm{g} / \mathrm{ml}$ synthetic somatostatin 1-14 (Peninsula Laboratories). Preabsorption abolished all punctate $\mathrm{DAB}$ reaction product.
To examine the expression of other peptides, cultures were fixed as described above and then incubated overnight with primary antibodies diluted 1:250 in blocking buffer followed by double PAP processing as described above. Antibodies used were rabbit anti-substance P (SP; INC Star), rabbit anti-vasoactive intestinal polypeptide (VIP; INC Star), rabbit anti-neuropeptide Y (NPY; Amersham). Sections of E17 chicken dorsal root and sympathetic ganglia were processed in parallel as positive controls.

For smooth-muscle-specific $\alpha$-actin immunocytochemistry, cultures fixed as described above were incubated for $1 \mathrm{hr}$ with a mouse monoclonal primary antibody specific for a smooth-muscle-specific isoform of $\alpha$-actin (Sigma Immunologicals) diluted 1:1600 in blocking buffer. This monoclonal antibody was raised against the $\mathrm{N}$-terminus of smoothmuscle-specific $\alpha$-actin, and in immunoblots, it reacts with aortic actin but not with actin from fibroblasts, striated muscle, or myocardium (Skalli et al., 1986). Antibody binding was detected using a fluoresceinconjugated secondary antibody (diluted 1:200 in blocking buffer; Cappel).

Cell culture. The choroid layers of 12-14-d-old chick eyes were isolated by cutting an $X$ into the back of the eye, removing the vitreous humor and neural retina, and separating the choroid/pigmented epithelium from the sclera. As much pigmented epithelium as possible was removed by touching sterile cotton to the exposed pigmented epithelium. The cleaned choroid was then cut into small pieces, incubated with collagenase [Worthington; $2 \mathrm{mg} / \mathrm{ml}$ in Earle's balanced salt solution (Gibco) for $20 \mathrm{~min}$ at $37^{\circ} \mathrm{C}$ ) followed by trypsin (Gibco; $0.2 \%$ in modified Puck's saline for $20 \mathrm{~min}$ at $37^{\circ} \mathrm{C}$ ), and triturated through a fire-polished Pasteur pipette. The dissociated cell suspension was preplated onto tissue-culture plastic for $45 \mathrm{~min}$ at $37^{\circ} \mathrm{C}$ to remove fibroblasts, then plated into the depression formed by a polylysine/laminin-coated plastic coverslip [100 $\mu \mathrm{g}$ poly-D-lysine (Sigma) for $8 \mathrm{hr}$, followed by an $8-\mathrm{hr}$ incubation with $2 \mu \mathrm{g}$ laminin (Gibco)] glued over the bottom of a $1-\mathrm{cm}$ hole cut in the center of a 35-mm tissue culture dish. Medium consisted of Eagle's minimal essential medium (MEM; Gibco) containing $2 \mathrm{~mm}$ glutamine, $6 \mathrm{mg} / \mathrm{ml}$ glucose, $50 \mathrm{U}$ penicillin, and $50 \mu \mathrm{g}$ streptomycin and supplemented with $10 \%(\mathrm{v} / \mathrm{v})$ horse serum, $2 \%(\mathrm{v} / \mathrm{v})$ chick embryo extract, and $10^{-5} \mathrm{M}$ cytosine arabinoside or $10^{-5} \mathrm{M}$ fluorodeoxyuridine.

Pectoral muscle myotubes and CG neuron cultures were prepared as previously described (Nishi and Berg, 1977). The dissociated suspensions of CG cells were plated onto previously established cultures of dissociated choroid cells, striated muscle myotubes, or onto polylysine/ laminin-coated tissue culture dishes. The co-cultured cells were grown in MEM containing glutamine, glucose, penicillin, and streptomycin (described above) and supplemented with $10 \%(\mathrm{v} / \mathrm{v})$ horse serum and $1 \%(\mathrm{v} / \mathrm{v})$ chick eye extract. The medium was changed every third day.

Preparation of conditioned medium. Choroid cell cultures for conditioned medium were prepared by incubating pieces of choroid tissue from embryonic day 14 (F.14) eyes in trypsin (Gibco; $0.05 \%$ in modified Puck's saline for $20 \mathrm{~min}$ at $37^{\circ} \mathrm{C}$ ) followed by trituration through a firepolished Pasteur pipette. The dissociated cells were plated into tissue culture flasks $\left(1-1.2 \times 10^{-6}\right.$ cells $/ 150-\mathrm{cm}^{2}$ flask $)$ in modified Leibovitz's L-15 (Mains and Patterson, 1973) containing glutamine, glucose, penicillin, and streptomycin as described above $\left(\mathrm{L} 15 \mathrm{CO}_{2}\right)$ and supplemented with $10 \%$ chicken serum (Gibco).

Conditioned medium was prepared by incubation of nearly confluent cultures with $\mathrm{L} 15 \mathrm{CO}_{2}$ supplemented with $0.1 \%$ horse serum for 4-5 d. Conditioned medium was concentrated by ammonium sulfate precipitation $\left(0.62 \mathrm{gm}\right.$ ammonium sulfate $/ \mathrm{ml}$ medium) overnight at $4^{\circ} \mathrm{C}$. The resultant pellet was resuspended in $0.1 \mathrm{M}$ sodium phosphate $(\mathrm{pH}, 7.3)$ and dialyzed against 2 changes of $0.1 \mathrm{~m}$ sodium phosphate $(\mathrm{pH}, 7.3)$ and 1 change of $\mathrm{L} 15 \mathrm{CO}_{2}$. In some cases, choroid-conditioned medium (ChCM) was concentrated by centrifugation through a Centriprep@ filter unit (Amicon) with a membrane cutoff of $10 \mathrm{kDa}$.

Cultures of CG were fed concentrated ChCM diluted into $\mathrm{L} 15 \mathrm{CO}_{2}$ and supplemented to a final concentration of $10 \%(\mathrm{v} / \mathrm{v})$ horse serum and $1 \%(\mathrm{v} / \mathrm{v})$ eye extract.

Cell counting. A bright-field microscope with a $40 \times$ objective was used to count the number of neurons and to determine the proportion of neurons containing SOM-IR. Every neuron within a "+" shaped pattern extending across each culture was counted and scored for SOMIR. A neuron was defined as an ovoid cell with an axonal process at least 2 cell diameters long. A neuron was scored as containing SOMIR if its cytoplasm contained punctate DAB reaction product. A I-way analysis of variances (ANOVA) and a Newman-Keuls multiple comparison test were used to assess the statistical significance of the results. 
Determination of choline acetyltransferase activity. Choline acetyltransferase (ChAT) was assayed using a modification of the method described by Fonnum (1975). Cultures were washed in modified Puck's saline and extracted in $0.05 \mathrm{M}$ sodium phosphate $(\mathrm{pH}, 7.5)$ containing $0.20 \mathrm{M} \mathrm{NaCl}, 0.5 \%$ Triton X-100, $5 \mathrm{mg} / \mathrm{ml}$ bovine serum albumin, 10 mM choline chloride, $0.2 \mathrm{~mm}$ eserine sulfate, $10 \mathrm{~mm}$ EDTA, and $5 \mathrm{~mm}$ dithiothreitol, then frozen and stored at $-70^{\circ} \mathrm{C}$. Aliquots of the cell homogenates were later thawed and assayed. For assays, 25- $\mu$ l aliquots of cell homogenate were incubated together with $5 \mu \mathrm{l}{ }^{3} \mathrm{H}$-acetylCoA for $30 \mathrm{~min}$ at $37^{\circ} \mathrm{C}$. The reaction was stopped by the addition of $1 \mathrm{ml}$ PBS, and the acetylcholine produced was separated from the substrates by the addition of $0.2 \mathrm{ml}$ tetraphenyl boron $(5 \mathrm{mg} / \mathrm{ml}$ in acetonitrile) and $4 \mathrm{ml}$ of a toluene-based scintillation fluid.

Retrograde labeling of ciliary neurons. Ciliary neurons were labeled by retrograde transport of fluorescent latex microspheres (Katz et al., 1984) in a protocol similar to that previously described for labeling quail CG neurons (Coulombe and Bronner-Fraser, 1986). Briefly, eyes together with their attached ciliary ganglia were dissected from E8 embryos. The choroid nerves, which are physically distinct from the ciliary nerve, were transected with electrolytically sharpened tungsten needles, and the canal of Schlemm was severed in 2 locations to prevent backflow of label into the region of the ciliary ganglion. Approximately $10-\mu l$ of a 1:4 latex microsphere: modified Puck's saline solution was then injected into the region of the iris. The eyes were then incubated at $37^{\circ} \mathrm{C}$ for 10 $12 \mathrm{hr}$ in culture medium in an atmosphere of $95 \% \mathrm{O}_{2}, 5 \% \mathrm{CO}_{2}$. This procedure was selective in initially labeling only neurons and labels approximately $25 \%$ of the total CG neurons. Labeled ganglia were then dissociated and cultured for $4 \mathrm{~d}$ in the presence of 5 -fold-concentrated $\mathrm{ChCM}$ prior to fixation and processing for anti-somatostatin immunocytochemistry.

\section{Results}

\section{Somatostatin expression in situ}

We first determined the developmental time course with which somatostatin appeared in CG neurons. At each embryonic stage mentioned, we examined immunostained sections of CG prepared from a minimum of 20 embryos. A few neurons with SOM-IR were detected within an occasional ganglion as early as stage 29 (6 d of incubation). By E6.5 (stage 30), all ganglia examined contained a few (estimated at $\leq 1 \%$ ) neurons with SOM-IR (Fig. 1a). The time at which SOM-IR could be consistently detected coincides with the stage following the extension of axons across the choroid layer (Meriney and Pilar, 1987). By E8 (stage 34), the proportion of neurons with SOM-IR had increased somewhat (estimated at $<10 \%$; see Fig. $1 b$ ), and by E14 (stage 44), approximately $1 / 2$ of the neurons contained SOMIR (confirming the observations of Epstein et al., 1988; see Fig. $1 c$ ). No further increases in the proportion of neurons with SOM-IR were noted.

\section{Cell culture of E8 CG neurons}

For examining the development of somatostatin expression in culture, E8 CG were used because $<10 \%$ of the neurons express SOM-IR at this stage, and because information about the survival and cholinergic development of cultured neurons from this developmental age is available (Nishi and Berg, 1979, 1981; Tuttle et al., 1980, 1983). To test whether somatostatin expression was induced by target tissue interaction, we co-cultured E8 (stage 34) CG neurons with dissociated choroid cells, skeletal muscle myotubes, or with ganglionic non-neuronal cells. In all these culture situations, non-neuronal cells from the ganglion were present, and the medium was supplemented with eye extract in order to support long-term survival, growth, and differentiation of these neurons in culture (Nishi and Berg, 1981). Increased expression of SOM-IR was only observed when CG neurons were cultured with choroid cells. Examples of neurons from these co-culture experiments are shown in Figure 2. Figure
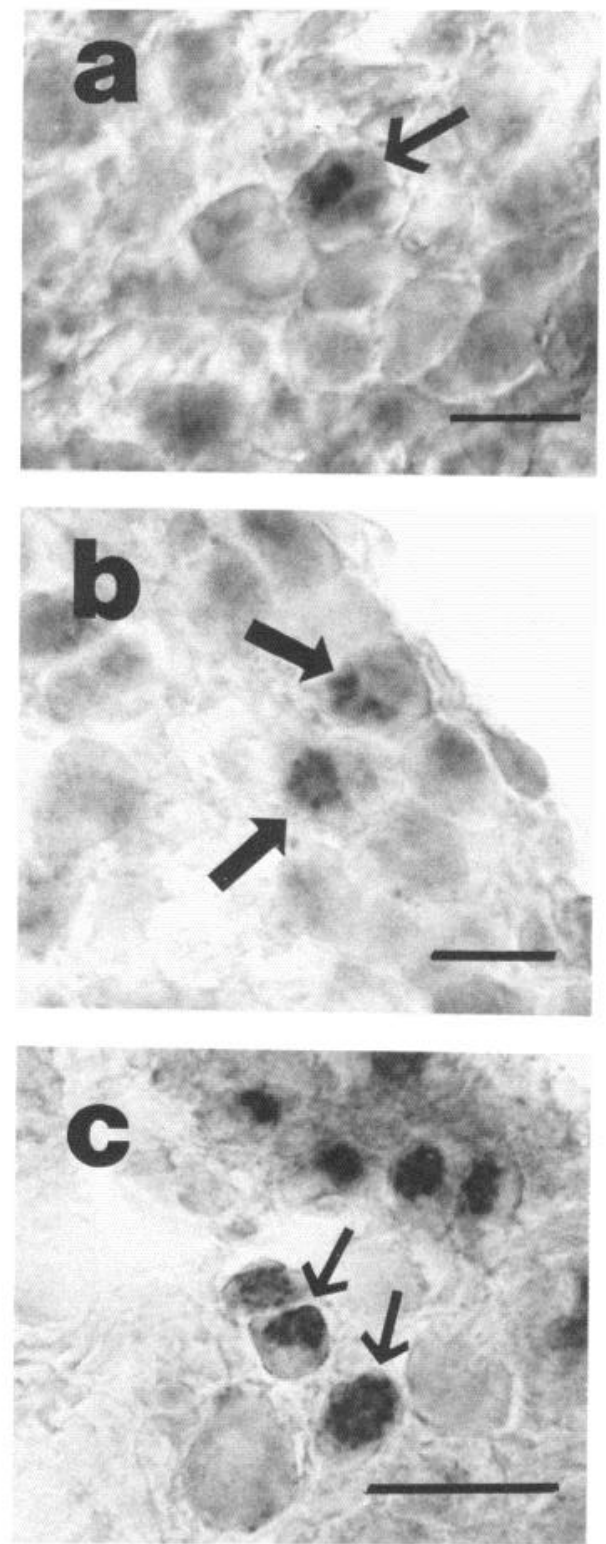

Figure 1. Somatostatinlike immunoreactivity in CG neurons during development in vivo: cryostat sections through CG fixed at varying stages of development. The arrows indicate neurons with SOM-IR. $a$, E6.5 (stage 30) CG. A few neurons with SOM-IR were consistently observed in sections of ganglia at this developmental stage. Differential interference contrast (Nomarski) was used. Scale bar, $15 \mu \mathrm{m}$. $b$, E8 (stage 34) CG. Neurons with SOM-IR were scattered throughout the ganglion, but were most frequently located near the ganglion periphery. Bright-field photomicrograph. Scale bar, $20 \mu \mathrm{m}$. $c$, E14 (stage 40) CG. By E14, neurons containing SOM-IR make up approximately $50 \%$ of the ganglion cell profiles, with a morphology characteristic of neurons (large ovoid cell bodies and large rounded nuclei). In general, neuronal cell profiles containing SOM-IR were smaller than unstained neurons and were located at the periphery of the ganglion. Bright-field photomicrograph. Scale bar, $20 \mu \mathrm{m}$.

$2 a$ is a photomicrograph of E8 CG neurons co-cultured with choroid cells and processed for anti-somatostatin immunocytochemistry. The dark, punctate DAB reaction product present in the cytoplasm of many of these neurons is indicative of SOMIR. A similar culture is illustrated in Figure $2 c$; however, these cells were reacted with primary antisera that had been preincubated with synthetic somatostatin, and all SOM-IR was abol- 
Figure 2. SOM-IR in cultured CG neurons. Neurons from E8 $(a-c)$ or E14 (d) CG were cultured with choroid cells $(a, c, d)$ or pectoral muscle myotubes (b) for $6 \mathrm{~d}$. SOM-IR is visible as a dark, punctate reaction product within the cell body. The arrows identify neurons with SOM-IR. Note the lack of SOM-IR in neurons cultured on pectoral muscle $(b)$ and when the antiserum was preabsorbed with $0.5 \mu \mathrm{g}$ synthetic somatostatin 1-14 (c). Scale bar, $20 \mu \mathrm{m}$.
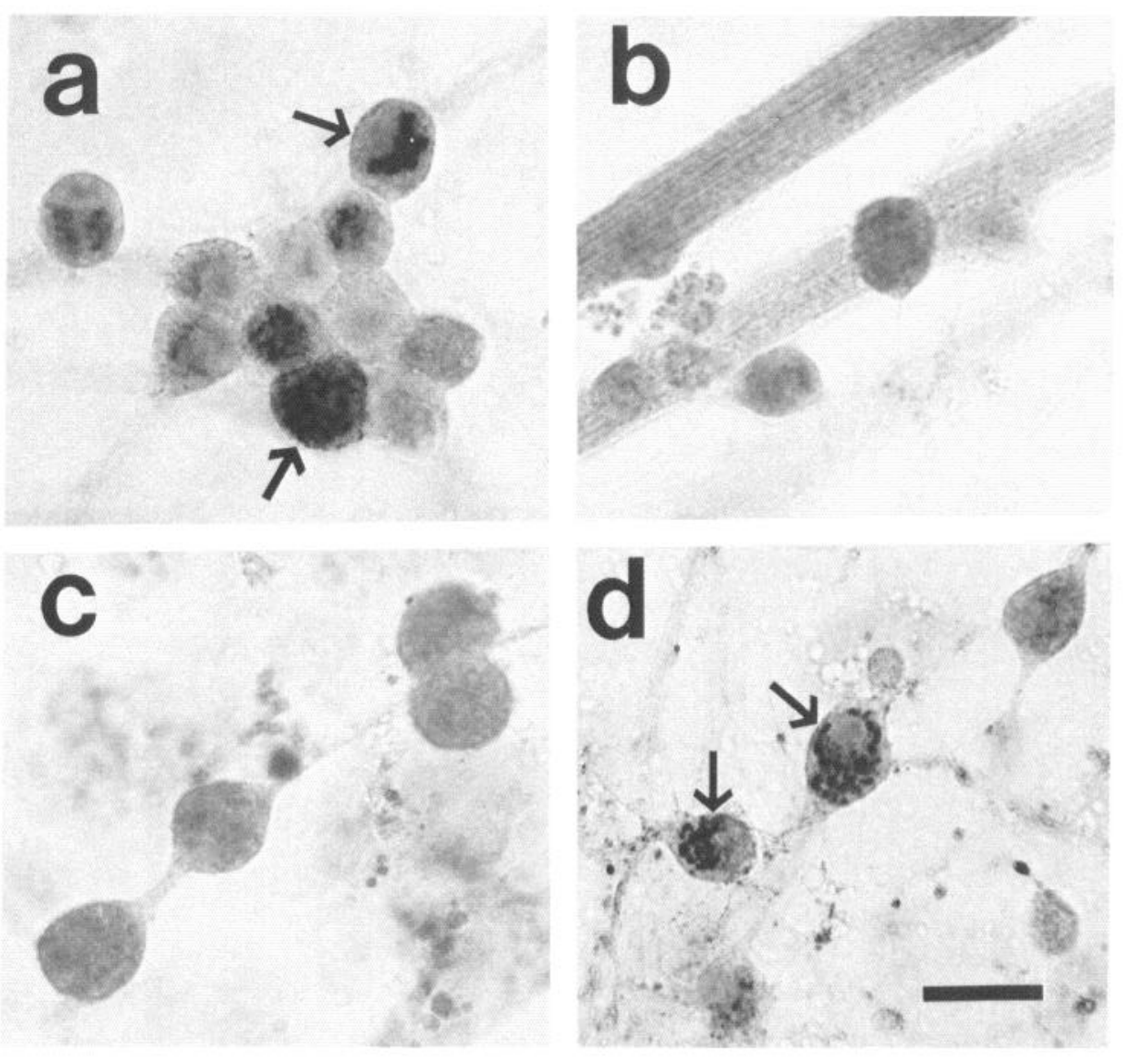

ished by this preincubation. CG neurons co-cultured with pectoral muscle myotubes are illustrated in Figure $2 b$. In these cultures, $>90 \%$ of pectoral cell nuclei were incorporated into myotubes, and most of these myotubes exhibited the crossstriations characteristic of well-differentiated myotubes. Very few neurons with SOM-IR were observed in these co-cultures with pectoral muscle.

The results of scoring co-cultured E8 CG neurons for SOMIR are illustrated in Figure $3 a$. One day after plating, the percentage of neurons containing detectable SOM-IR was low in all 3 culture conditions. This was consistent with the finding that cryostat sections of freshly dissected E8 ciliary ganglia contained only a small number of cells with SOM-IR (Fig. 2a). Over the 6-d culture period, the percentage of CG neurons containing SOM-IR increased in cultures containing choroid cells. In contrast, the percentage of CG neurons containing SOM-IR in cultures of CG neurons grown with pectoral muscles or with ganglionic non-neuronal cells remained low $(<3 \%)$ during the same time period. The total number of neurons did not significantly change during the culture period in any of these coculture paradigms (Fig. $3 b$ ). Similarly, increases in ChAT activity per culture were comparable for all 3 co-culture conditions (Fig. 3c). Thus, choroid cells specifically influenced expression of SOM-IR without affecting the expression of ChAT in E8 CG neurons.

\section{Cell culture of E13-14 CG neurons}

We also tested whether choroid cells were necessary to maintain the expression of SOM-IR in more mature CG neurons. We used E13-14 CG to examine the maintenance of somatostatin expression because, by this stage in situ, approximately $1 / 2$ of the CG neurons contained SOM-IR, and no further increases in the number of neurons expressing SOM-IR were observed at later stages. E13-14 CG neurons were cultured in paradigms similar to that described above and then tested for SOM-IR. An example of E13-14 CG neurons co-cultured with choroid cells is illustrated in Figure $2 d$. The percentage of neurons containing SOM-IR after $1 \mathrm{~d}$ in culture was approximately $50 \%$ in all 3 culture conditions (Fig. $4 a$ ). In cultures with striated muscle or ganglionic non-neuronal cells, the proportion of neurons containing SOM-IR declined to $<10 \%$ by $5 \mathrm{~d}$ after plating. In contrast, approximately $50 \%$ of the E13-14 CG neurons co-cultured with choroid cells contained SOM-IR throughout the 7-d period examined. Among the culture conditions, there were no significant differences in the number of neurons (Fig. $4 b$ ), nor were there evident differences in ChAT expression during the $5 \mathrm{~d}$ in which SOM-IR declined (Fig. 4c). Thus, CG neurons that have already begun to express SOM-IR in vivo appear to require an interaction with choroid cells to maintain expression in culture.

\section{Expression of other neuropeptides}

We tested E8 CG neurons co-cultured for $6 \mathrm{~d}$ with choroid cells for immunoreactivity against other neuropeptides commonly found within autonomic neurons. In duplicate plates from 2 separate experiments, no NPY-, SP-, or VIP-immunoreactive neurons were present in E8 CG neurons co-cultured with choroid cells. Cryostat sections of E17 dorsal root and sympathetic ganglia that were processed concurrently with these cultures 

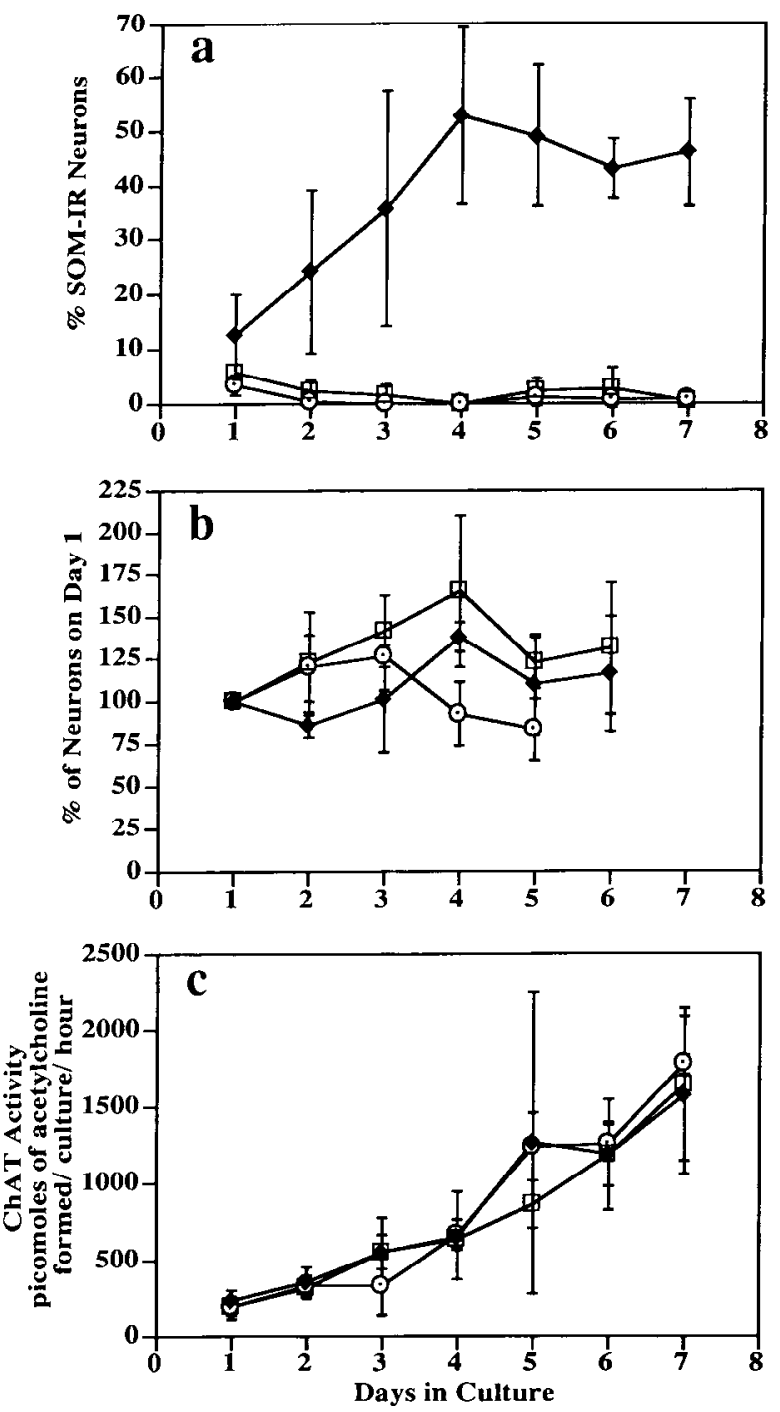

Figure 3. Somatostatin expression, survival, and cholinergic differentiation in cultures of E8 CG neurons under 3 different co-culture conditions. E8 CG were dissociated, and the neurons along with the ganglion-derived non-neuronal cells were cultured with choroid cells (solid diamonds), striated muscle myotubes (open squares), or in the absence of other target cells (open circles). Cultures were harvested at daily intervals and processed in order to measure the percentage of neurons with SOM-IR $(a)$, total neuronal survival $(b)$, and ChAT activity ( $c$ ). Each point represents the average of 3-4 separatc culture dishes from 2-4 platings. ChAT activity in CG neurons with ganglionic nonneuronal cells is represented by the average of 2-3 dishes from 2 separate plantings. Error bars indicate SD. After the second day of culture, the percentage of SOM-IR neurons significantly ( $p \leq 0.05$; assessed by I-way ANOVA followed by a Newman-Keuls multiple comparison test) increased in CG neurons that were co-cultured with choroid cells. No significant differences were found between these culture conditions in either the number of neurons or in ChAT activities.

contained neurons immunoreactive with NPY, SP, or VIP, as did sister cultures processed for anti-somatostatin immunoreactivity. It thus appeared that the presence of choroid cells was insufficient to induce a general expression of neuropeptides in cultured CG neurons.

\section{Smooth-muscle-specific $\alpha$-actin immunocytochemistry}

To determine if our choroid cell cultures contained differentiated smooth muscle cells, we staincd some of these cultures with
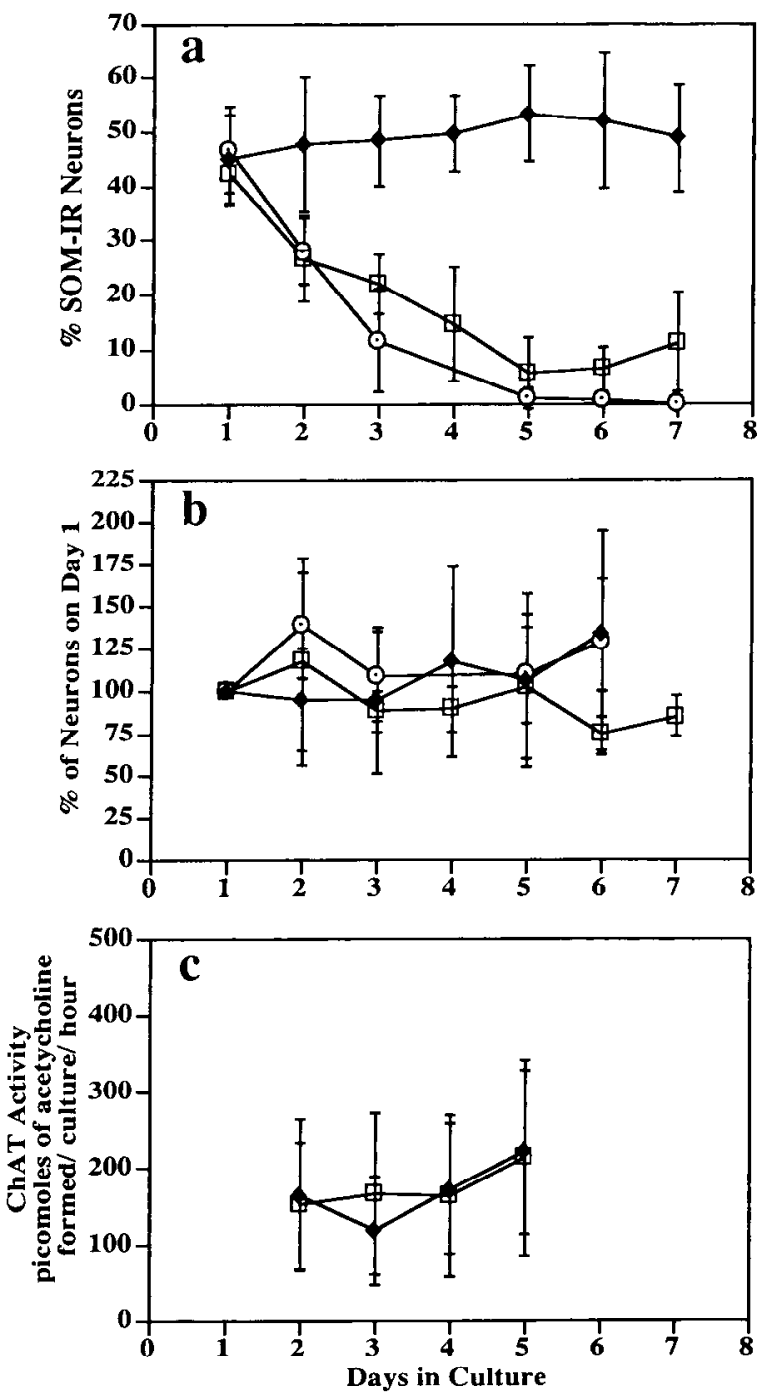

Figure 4. Expression of SOM-IR, survival, and cholinergic differentiation in cultures of E13-14 CG neurons. E14 CG were dissociated and cultured with choroid cells (solid diamonds), striated muscle myolubes (open squares), or in the absence of any other target cells (open circles). At daily intervals, cultures were harvested and processed in order to measure the percentage of neurons with SOM-IR $(a)$, total neuronal survival $(b)$, and ChAT activity $(c)$. Each point represents the average of 3-4 separate dishes from 3-4 platings. ChAT activity is represented by the average of 4 separate dishes from 2 platings. ChAT activity per culture is less than that found in E8 cultures (Fig. 3c), at least in part because the cultures of E13-14 CG contain only $1 / 10$ of the number of neurons found in E8 CG cultures. Error bars indicate SD. After the second day of culture, the percentage of SOM-IR neurons significantly ( $p \leq 0.05$; assessed by 1 -way ANOVA followed by a Newman-Keuls multiple comparison test) declined in CG neurons that were not co-cultured with choroid cells. No significant differences were found between these culture conditions in either the number of neurons or in ChAT activities.

a monoclonal antibody directed against the $\mathrm{N}$-terminus of smooth-muscle-specific $\alpha$-actin (Sigma Immunological). This antibody stained long fibers within many cells in the choroid cell cultures (Fig. 5). That this antibody did not recognize all forms of actin was suggested by the observation that many fibroblasts and ganglionic non-neuronal cells were not stained for smooth-muscle-specific $\alpha$-actin. Thus, our cultures of choroid cells contained differentiated smooth muscle cells that are the in vivo targets of somatostatin-containing CG neurons. 


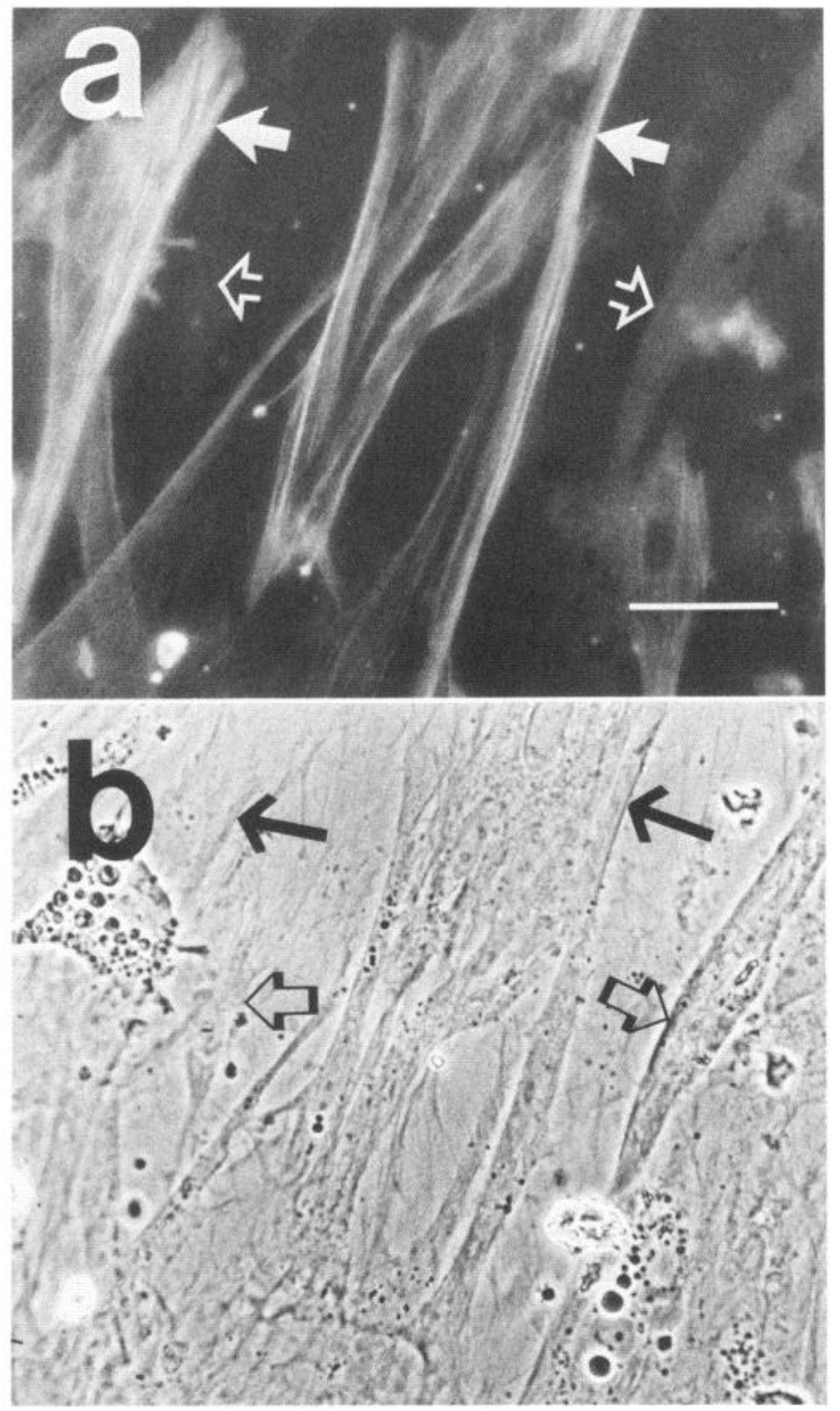

Figure 5. Smooth-muscle-specific $\alpha$-actin-like immunoreactivity in choroid cell cultures. Cultures of dissociated choroid layer cells were established, fixed, and reacted with a monoclonal antibody raised against the $\mathrm{N}$-terminus of smooth-muscle-specific $\alpha$-actin (Sigma Immunochemicals) followed by a fluorescein-conjugated secondary antibody. $a$ is a representative field of view photographed with epifluorescence optics; $b$ is the same field photographed with phase-contrast optics. Solid arrows point out examples of immunoreactive cells; open arrows indicate unstained cells. Scale bar, $15 \mu \mathrm{m}$.

\section{Somatostatin expression with conditioned medium}

As a first step in understanding the mechanism by which choroid cells were able to stimulate the expression of SOM-IR, we asked whether the effect was mediated by a soluble factor or required direct cell contact. Accordingly, we collected medium from confluent choroid cultures (ChCM). The proportion of neurons with SOM-IR after $3 \mathrm{~d}$ of culture in varied doses of ChCM is shown in Figure 6. The response of CG neurons to ChCM was dosage dependent, with a half-maximal response between 2.5- and 5 -fold concentration and a plateau at about a 10 -fold concentration of ChCM. A greater response to $\mathrm{ChCM}$ was found after longer culture periods. Figure $7 a$ shows the response in percent SOM-IR neurons over time with a 5-fold concentration of ChCM.
The proportion of neurons with SOM-IR was maximal after 9 d in culture, with greater than $90 \%$ of the neurons expressing SOM-IR. Although there was a gradual decrease in the total number of neurons in these cultures (Fig. $7 b$ ), this effect was insufficient to account for changes in the proportion of neurons with SOM-IR.

As an initial step in characterizing the $\mathrm{ChCM}$ component that stimulates somatostatin expression, we concentrated some batches of $\mathrm{ChCM}$ with a Centriprep@ (Amicon) filter apparatus. This device concentrates the components that are of an apparent size greater than $10 \mathrm{kDa}$. CG neurons were cultured in the ChCM concentrated by the filter or in the filter flow-through. None of the CG neurons grown in the filter flow-through contained SOM-IR, while in contrast, $73 \pm 7 \%$ SD of the neurons grown in the filter-concentrated ChCM contained SOM-IR. The soluble factor responsible for stimulating SOM-IR thus had an apparent size equal to or larger than $10 \mathrm{kDa}$.

\section{Somatostatin expression in retrogradely labeled ciliary neurons}

The observation that $90 \%$ of the CG neurons in culture were induced to express SOM-IR with ChCM suggested that ciliary neurons, which do not normally express SOM-IR in vivo, could be induced to express SOM-IR. A direct test of this was performed by exposing retrogradely labeled ciliary neurons to $\mathrm{ChCM}$ in culture for $4 \mathrm{~d}$. A total of 618 neurons were scored in 7 different cultures. In these cultures, $24 \pm 5 \%$ SD of the total neurons were labeled with fluorescent latex microspheres. Of the labeled neurons, $57 \pm 13 \%$ SD also contained SOM-IR. This percentage of retrogradely labeled neurons expressing SOMIR did not significantly differ from the total number of neurons expressing SOM-IR in the cultures examined ( $57 \pm 6 \%$ SD). Figure 8 is a photomicrograph showing some of these neurons. This result suggests that some ciliary neurons are able to express SOM-IR when exposed to ChCM.

\section{Discussion}

The avian CG contains 2 subpopulations of cholinergic neurons: ciliary and choroid neurons. In vivo, only the choroid neurons utilize the neuropeptide somatostatin as a neuromodulatory agent (Epstein et al., 1988; Gray et al., 1989, 1990). These studies were undertaken to identify how this differential expression of somatostatin is controlled. We have identified an influence from the appropriate target tissue, the choroid layer, that will induce and maintain somatostatin expression in cultured CG neurons.

Our finding of initial somatostatin expression in stage 29 and consistent somatostatin expression at stage 30 coincides with the observation that neurofilamentlike immunoreactive neurites from the $\mathrm{CG}$ are first observed spreading over the choroid layer as early as stage 29 (Meriney and Pilar, 1987). This is consistent with the notion that a target interaction controls somatostatin expression. Our use of the sensitive double PAP technique for immunocytochemical detection (Vacca et al., 1980; Ordronneau et al., 1981), together with the ease of recognizing the discrete punctate intracellular localization of SOM-IR, made us confident that a lack of detectable SOM-IR within a neuron reflected an insignificant level of somatostatin expression.

By testing whether target interactions in cell culture could regulate somatostatin expression in CG neurons, we found that cells of the choroid layer support both the induction and the maintenance of SOM-IR. This result could not be accounted for by differential cell survival. Furthermore, the results showed 


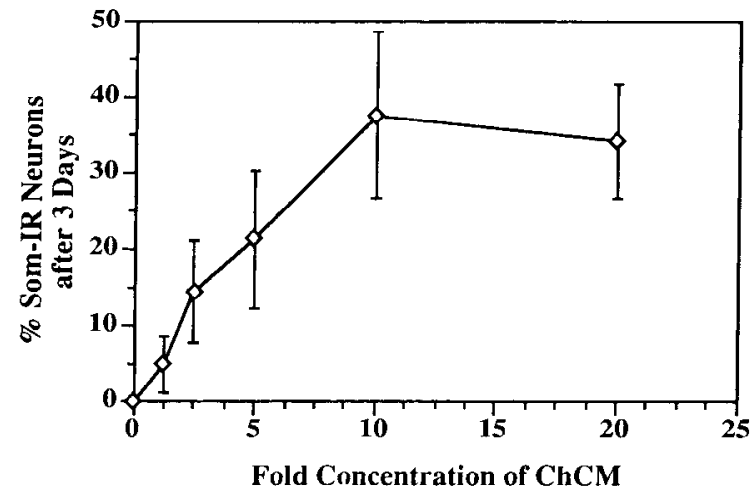

Figure 6. Effects of ChCM on SOM-IR expression. E8 CG neurons were cultured for $3 \mathrm{~d}$ in medium supplemented with varying amounts of concentrated ChCM. This figure shows the sum of results from 3 separate preparations of $\mathrm{ChCM}$ in 3 separate platings. Error bars indicate SD.

that co-culture with myotubes or with ganglionic non-neuronal cells was adequate for optimal growth and differentiation of CG neurons because there were no substantial differences in ChAT activity under all the culture conditions tested.

The absence of apparent differences in ChAT activity under these different co-culture conditions is also significant because it indicated that, for CG neurons, the regulation of small-molecule neurotransmitter expression is independent of the regulatory mechanisms for neuropeptide expression. This result is in contrast to results in the rat superior cervical ganglion (SCG). In this sympathetic ganglion, neuropeptide expression appears to be coordinately regulated with classical neurotransmitter levels. For example, in dissociated rat SCG neurons, culture conditions that increase ChAT activity also increase levels of SP, and changes in tyrosine hydroxylase (TH) activity are correlated with changes in somatostatin content (Kessler, 1984; Adler and Black, 1986). Moreover, different factors-cholinergic differentiation factor, membrane-associaled neurotransmitter stimulating factor (MANS), and a partially purified membrane-derived factor-all increase $\mathrm{ChAT}$ activity along with SP expression in cultured SCG neurons (Wong and Kessler, 1987; Lee et al., 1990; Nawa and Patterson, 1990). Although SP appears linked with ChAT, and somatostatin appears to be co-regulated with $\mathrm{TH}$, the cellular mechanisms mediating these influences appear to be separable (Kessler, 1985). Moreover, in vivo, the same coordinate regulation of peptide and small-molecule transmitter is not always apparent. For example, though rat SCG neurons innervating the footpad are cholinergic (Landis and Keefe, 1983; Leblanc and Landis, 1986; Stevens and Landis, 1987), their terminals contain VIP (Yodlowski et al., 1984) and do not appear to contain SP. It is therefore likely that the apparent coregulation of neurotransmitters in the SCG reflects an underlying heterogeneity in the types of neurons present, rather than a coordinate regulation of peptide and small-molecule transmitters. For cultured chicken CG neurons, it is appropriate that $\mathrm{ChAT}$ and somatostatin be independently regulated because, of the 2 subpopulations of cholinergic neurons, only the choroid neurons employ somatostatin as a neuromodulator in vivo (Epstein et al., 1988; Gray et al., 1989, 1990).

The influence of choroid cells upon neurotransmitter expression in CG neurons appears to be specific in that CG neurons that expressed somatostatin did not contain detectable immu-
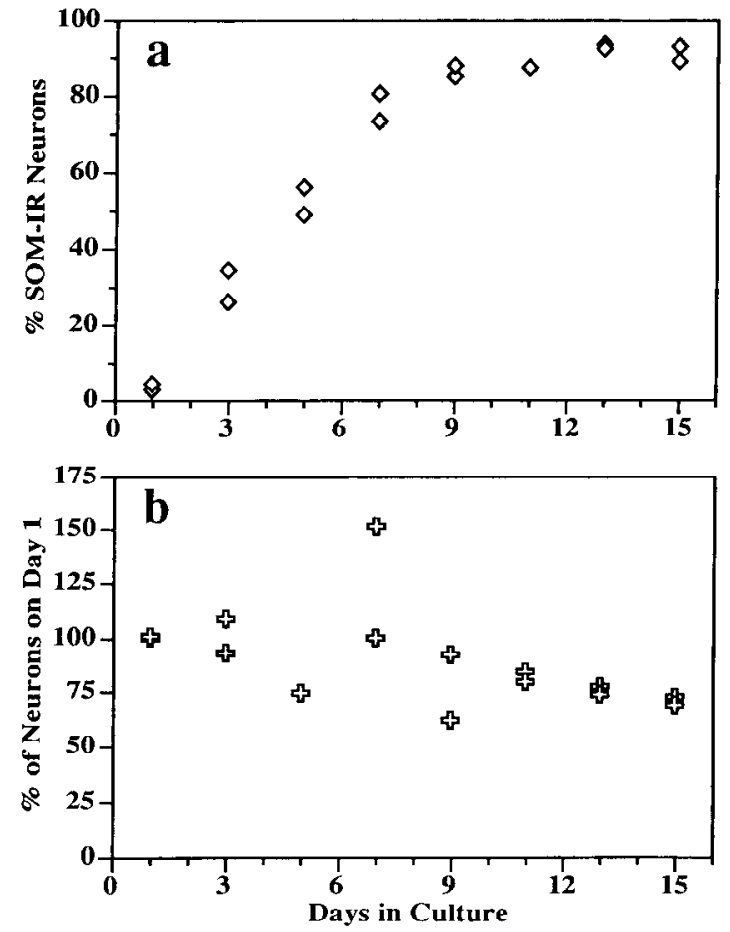

Figure 7. Time course of response to ChCM. E8 CG neurons were cultured in medium containing 5-fold-concentrated ChCM. $a$ shows the percentage of SOM-IR expressed with time in culture; $b$ shows the total number of neurons counted in these same cultures. Because of the variation in response in platings and potency of ChCM, results from only 1 representative plating are shown here. Each point represents the number counted in 1 culture. Similar results were obtained in 2 other experiments. Although there was a gradual decline in the number of neurons present, this decline was not apparent until after $9 \mathrm{~d}$ of culture, when the proportion of SOM-IR neurons had reached a maximum. Thus, this minor decline was not sufficient in magnitude to explain the changes in the percentage of SOM-IR observed in $a$.

noreactivity for NPY, VIP, or SP. This result is in accord with the lack of evidence for expression of any other neuropeptides within CG neurons in situ and contrasts with the observation that conditioned medium factors that affect the synthesis of one neuropeptide in rat SCG neurons also increase the synthesis of other neuropeptides (Nawa and Patterson, 1990; Nawa and Sah, 1990). These differences in responses between chick parasympathetic neurons and rat sympathetic neurons are most likely to be due to the lower degree of neuronal heterogeneity in the CG.

Our observation that the factor stimulating somatostatin expression is soluble and secreted from choroid cells is consistent with other studies in which soluble factors have been shown to influence neurotransmitter expression (Patterson and Chun, 1977; Kessler et al., 1984; Fukada, 1985; Zurn and Do, 1988; Denis-Donini, 1989; Iacovitti et al., 1989; Martinou et al., 1989; Nawa and Patterson, 1990; Nawa and Sah, 1990) and differs from membrane-contact-mediated factors that also have been reported (Hawrot, 1980; Adler and Black, 1985, 1986; Kessler et al., 1986; Gray and Tuttle, 1987; Wong and Kessler, 1987; Adler et al., 1989). Preliminary charcterization of size suggests that the somatostatin-stimulating activity (SSA) is a macromolecule and not a small metabolite (Zurn and Do, 1988) or a neuropeptide (Denis-Donini, 1989). Interestingly, the eye extract used to provide trophic support of the CG neurons (Nishi and Berg, 1981) was insufficient to support somatostatin ex- 
Figure 8. SOM-IR in retrogradely labeled ciliary neurons. E8 CG were retrogradely labeled through the ciliary nerve, dissociated, and cultured for $4 \mathrm{~d}$ in 10-fold-concentrated $\mathrm{ChCM}$. After processing for somatostatin immunocytochemistry, bead-labeled neurons that also contained SOM-IR were found. $a$ is the bright-field micrograph of the same field of view observed with fluorescence optics in $b$. Examples of another field of view are shown in $c$ and $d$. Solid arrows identify a neuron with SOM-IR; open arrows designate an unstained neuron. In a total of 618 neurons scored, $23 \pm 5 \%$ SD were microsphere labeled, and of these $57 \pm 13 \%$ SD also contained SOM-IR, suggesting that ciliary neurons can express somatostatin. Scale bar, $20 \mu \mathrm{m}$.
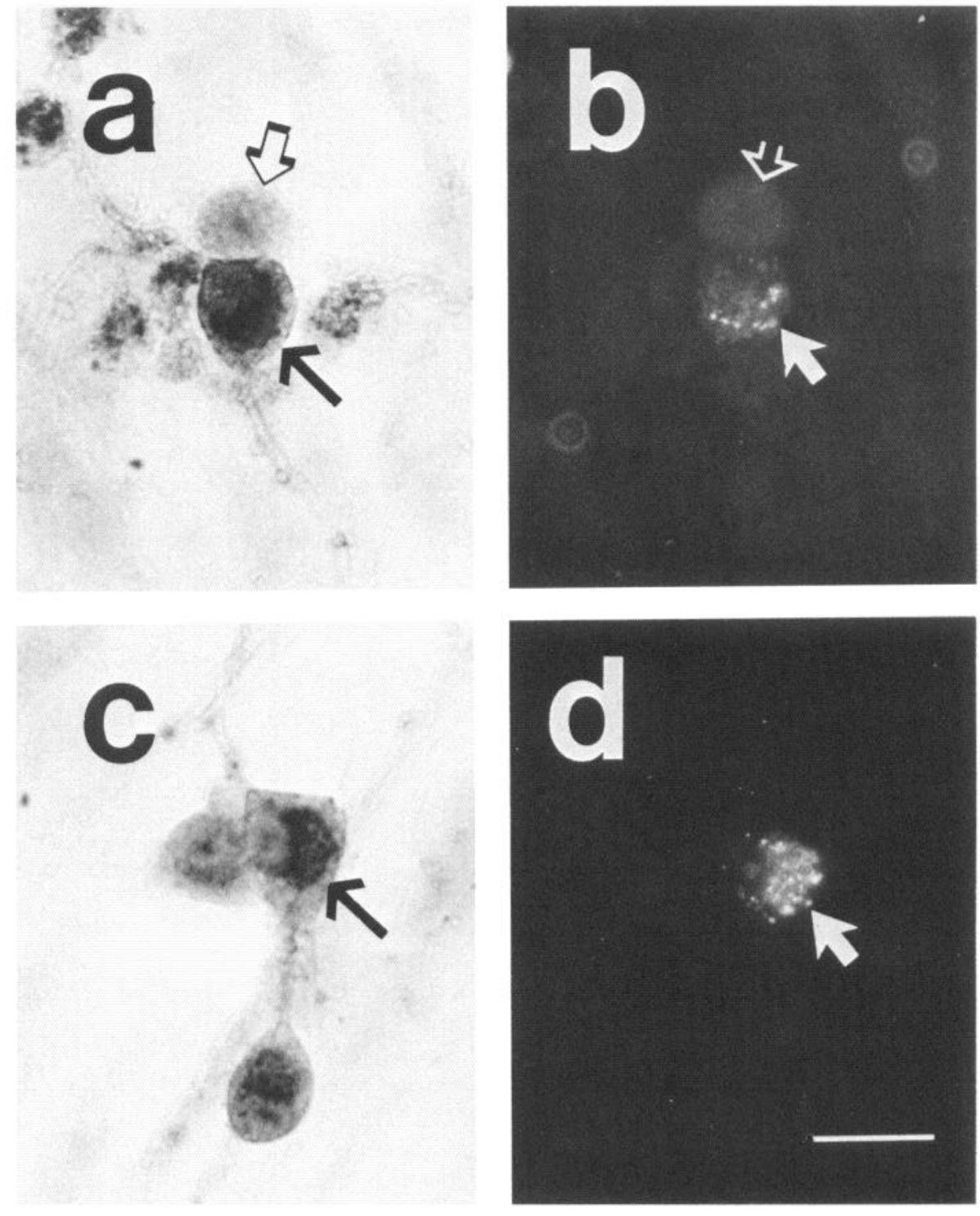

pression, even though a proportion of this extract was derived from choroid tissue. While it is possible that the titer of SSA in this extract is extremely low, this possibility is difficult to test because higher concentrations of eye extract are toxic to the CG neurons (R. Nishi, unpublished observations).

Our retrograde labeling experiments suggest that neurons that do not project to the choroid layer can be induced to express somatostatin by SSA. One assumption of this interpretation is that, by cutting all visible choroid nerves, no choroid neurons would be retrogradely labeled. In the absence of any other means to independently distinguish choroid from ciliary neurons at E8, it is impossible to completely exclude the possibility that some choroid neurons would be retrogradely labeled and hence express SOM-IR. However, inadvertently labeled choroid neurons would be likely to constitute only a small proportion of the total number of retrogradely labeled neurons and hence could not account for the large percentage $(57 \%)$ of labeled neurons that also expressed SOM-IR when exposed to SSA. Another assumption we have made is that no ciliary neurons express somatostatin. Because a few large neurons with SOM-IR have been reported in late embryonic and hatchling chicks (Epstein et al., 1988; Gray et al., 1990), it may be possible that a minority of ciliary neurons are normally fated to express somatostatin, and that this is the population that we have identified; however, the number of retrogradely labeled neurons that we have induced to express SOM-IR cannot be accounted for by the small percentage of ciliary neurons with SOM-IR reported in vivo. Together with the observation that more than $90 \%$ of E8 CG neurons contain SOM-IR after $9 \mathrm{~d}$ in culture with $\mathrm{ChCM}$, the retrograde labeling results indicate that many ciliary neurons that would not have normally produced somatostatin in vivo express somatostatin under the influence of SSA.

Because vascular smooth muscle in the choroid layer is the normal target in vivo for somatostatin-containing CG neurons, it is attractive to propose that induction and maintenance of the somatostatin phenotype of SSA be target specific. However, 2 qualifications to this conclusion must be stated. First, pectoral muscle, and not iris or ciliary body, was used as the source of striated muscle in the co-culture experiments. Pectoral muscle is not normally innervated by CG neurons, though studies in culture have demonstrated that CG neurons readily form synapses on pectoral muscle myotubes (Nishi and Berg, 1977; Tut- 
tle et al., 1980; Role et al., 1985), and that factors produced by the myotubes support full expression of the cholinergic phenotype in CG neurons. Although it would have been preferable to use iris/ciliary body rather than pectoral muscle, iris/ciliary body cultures are difficult to establish, and sufficient quantities of cells are difficult to obtain. In addition, the iris/ciliary body is continuous with the choroid layer; hence, cultures completely free of choroid cell contamination cannot be obtained. Second, though our observation that cultures of choroid cells contain numerous cells with smooth-muscle-specific $\alpha$-actin-like immunoreactivity is consistent with the idea that somatostatin expression is stimulated by smooth muscle, there are also other cell types within these cultures, including endothelial cells, fibroblasts, and pigmented retinal epithelial cells. A contribution from these other cell types cannot be ruled out. Moreover, target cell stimulation of somatostatin expression might involve an indirect influence from other cells types within the choroid layer. Thus, the actual cell types responsible for stimulating somatostatin expression are not yet known.

Nonetheless, the influence of choroid cells appears to be appropriate in that the choroid cell layer normally receives somatostatin innervation from the CG. In contrast, though there are numerous examples of non-neural cells affecting neuropeptide transmitter expression in neurons (Mudge, 1981; Kessler, 1984; Nawa and Sah, 1990), there are few examples of the influence being found in the appropriate target tissue. One example of this is the stimulation of VIP expression in sympathetic neurons by sweat glands (Schotzinger and Landis, 1988; Stevens and Landis, 1990). A counterexample is the stimulation of substance $P$ expression in rat SCG neuron cultures by pineal glands, though substance $P$ is not found within the SCG neurons innervating the pineal (Kessler, 1984). Whether the specificity of somatostatin expression by CG neurons in vivo is due to a differential expression of SSA in choroid smooth muscle but not iris or ciliary body awaits the purification of SSA and the subsequent production of antibodies or CDNA probes to examine the distribution of SSA.

\section{References}

Adler JE, Black IB (1985) Sympathetic neuron density differentially regulates transmitter phenotype expression in culture. Proc Natl Acad Sci USA 82:4296-4300.

Adler JE, Black IB (1986) Membrane contact regulates transmitter phenotypic expression. Dev Brain Res 30:237-241.

Adler JE, Schleifer LS, Black IB (1989) Partial purification and characterization of a membrane-derived factor regulating neurotransmitter phenotypic expression. Proc Natl Acad Sci USA 86:1080-1083.

Black IB, Adler JE, Dreyfus CF, Friedman WF, LaGamma EF, Roach AH (1987) Biochemistry of information storage in the nervous system. Science 236:1263-1268.

Chiappinelli VA, Giacobini E, Pilar G, Uchimura H (1976) Induction of cholinergic enzymes in chick ciliary ganglion and iris muscle cells during synaptic formation. J Physiol (Lond) 257:749-766.

Coulombe JN, Bronner-Fraser ME (1986) Cholinergic neurones acquire adrenergic neurotransmitters when transplanted into an embryo. Nature 324:569-572.

Coulombe JN, Bronner-Fraser ME (1990) Development of cholinergic traits in the quail ciliary ganglion: expression of choline acetyltransferase-like immunoreactivity. Neuroscience 37:259-270.

Denis-Donini S (1989) Expression of dopaminergic phenotypes in the mouse olfactory bulb induced by the calcitonin gene-related peptide. Nature 339:701-703.

Eckenstein FP, Esch F, Holbert T, Blacher RW, Nishi R (1990) Purification and charactcrization of a trophic factor for embryonic peripheral neurons: comparison with fibroblast growth factors. Neuron $4: 623-631$
Epstein ML, Davis JP, Gelman LE, Lamb JR, Dahl JL (1988) Cholinergic neurons of the chicken ciliary ganglion contain somatostatin. Neuroscience 25:1053-1060.

Fonnum $F$ (1975) A rapid radiochemical method for the determination of choline acetyltransferase. J Neurochem 24:407-409.

Fukada K (1985) Purification and partial characterization of a cholinergic neuronal differentiation factor. Proc Natl Acad Sci USA 82 : 8795-8799.

Gray DB, Tuttle JB (1987) [ $\left.{ }^{3} \mathrm{H}\right]$ acetylcholine synthesis in cultured ciliary ganglion neurons: effects of myotube membranes. Dev Biol 119:290-298.

Gray DB, Pilar R, Ford MJ (1989) Opiate and peptide inhibition of transmitter release in parasympathetic nerve terminals. J Neurosci 9: 1683-1692.

Gray DB, Zelazny D, Manthay N, Pilar G (1990) Fndogenous modulation of $\mathrm{ACH}$ release by somatostatin and the differential roles of $\mathrm{Ca}^{2+}$ channels. J Neurosci 10:2687-2698.

Hamburger V, Hamilton HL (1951) A series of normal stages in the development of the chick embryo. J Morphol 88:49-92.

Hawrot E (1980) Cultured sympathetic neurons: effects of cell-derived and synthetic substrata on survival and development. Dev Biol 74: 136-151.

Iacovitti L, Evinger MJ, Joh TH, Reis DJ (1989) A muscle derived factor(s) induces expression of a catecholamine phenotype in neurons of cultured rat cerebral cortex. J Neurosci 9:3529-3537.

Johnson DA, Pilar G (1980) The release of acetylcholine from postganglionic cells bodies in response to depolarization. $J$ Physiol (Lond) 299:605-619.

Katz IC, Burkhalter A, Dreyer WJ (1984) Fluorescent latex microspheres as a retrograde neuronal marker for in vivo studies of visual cortex. Nature 310:498-500.

Kessler JA (1984) Environmental co-regulation of substance P, somatostatin and neurotransmitter synthesizing enzymes in cultured sympathetic neurons. Brain Res 321:155-159.

Kessler JA (1985) Differential regulation of peptide and catecholamine characters in cultured sympathetic neurons. Neuroscience 15:827839 .

Kessler JA (1986) Differential regulation of cholinergic and peptidergic development in the rat striatum in culture. Dev Biol 113:77-89.

Kessler JA, Adler JE, Jonakait GM, Black IB (1984) Target organ regulation of substance $P$ in sympathetic neurons in culture. Dev Biol 103:71-79.

Kessler JA, Conn G, Hatcher VB (1986) Isolated plasma membranes regulate neurotransmitter expression and facilitate effects of a soluble brain cholinergic factor. Proc Natl Acad Sci USA 83:3528-3532.

Landis SC (1990) Target regulation of neurotransmitter phenotype. Trends Neurosci 13:344-350.

Landis SC, Keefe D (1983) Evidence for neurotransmitter plasticity in vivo: developmental changes in properties of cholinergic sympathetic neurons. Dev Biol 112:222-229.

Landmesser L, Pilar G (1974) Synapse formation during embryogenesis in ganglion cells lacking a periphery. J Physiol (Lond) 241:715736.

Leblanc G, Landis SC (1986) Development of choline acetyltransferase activity in the cholinergic sympathetic innervation of sweat glands. J Neurosci 6:260-265.

Leblanc $G$, I andis SC (1988) Target specificity of neuropeptide Y-like immunoreactive cranial parasympathetic neurons. J Neurosci 8:146-155.

Lee JM, Adler JE, Black IB (1990) Regulation of neurotransmitter expression by a membrane-derived factor. Exp Neurol 108:109-113.

Lin LFH, Mismer D, Lile JD, Butler LG, Armes ET, Vannice JL, Collins F (1989) Purification, cloning, and expression of ciliary neurotrophic factor (CNTF). Science 246:1023-1025.

Lundberg JM, Hokfelt T, Anggard A, Terenius L, Elde R, Markey K, Goldstein M, Kimmel J (1982) Organizational principles in the peripheral sympathetic nervous system: subdivision by coexisting peptides (somatostatin-, avian pancreatic polypeptide-, and vasoactive intestinal polypeptide-like immunoreactive materials). Proc Natl Acad Sci USA 79:1303-1307.

Macrae IM, Furness JB, Costa M (1986) Distribution of subgroups of noradrenaline neurons in the coeliac ganglion of the guinea-pig. Cell Tissue Res 244:173-180.

Mains R, Patterson PH (1973) Primary cultures of dissociated sympathetic neurons. I. Establishment of long-term growth in culture and studies of differentiated properties. J Cell Biol 59:329-345. 
Martinou JC, Le Van Thai $\Lambda$, Cassar G, Roubinel F, Weber MJ (1989) Characterization of two factors enhancing choline acetyltransferase activity in cultures of purified rat motoneurons. J Neurosci 9:36453656.

Marwitt R, Pilar G, Weakly JN (1971) Characterization of two ganglion cell populations in avian ciliary ganglia. Brain Res 25:317-334.

McMahon SB, Gibson S (1987) Peptide expression is altered when afferent nerve reinnervates inappropriate tissue. Neurosci Lett 73:915.

Meriney SD, Pilar G (1987) Cholinergic innervation of the smooth muscle cells in the choroid coat of the chick eye and its development. J Neurosci 7:3827-3839.

Mudge AW (1981) Effect of the chemical environment on levels of substance $P$ and somatostatin in cultured neurones. Nature 292:764765

Narayanan $\mathrm{CH}$, Narayanan $\mathrm{Y}$ (1978) On the origin of the ciliary ganglion in birds, studied by the method of interspecific transplantation of embryonic brain regions between quail and chick. J Embryol Exp Morphol 47:137-148.

Nawa H, Patterson PH (1990) Separation and partial characterization of neuropeptide-inducing factors in heart cell conditioned medium. Neuron 4:269-277.

Nawa H, Sah DWY (1990) Different biological activities in conditioned media control the expression of a variety of neuropeptides in cultured sympathetic neurons. Neuron 4:279-287.

Nishi R, Berg DK (1977) Dissociated ciliary ganglion neurons in vitro: survival and synapse formation. Proc Natl Acad Sci USA 74:51715175.

Nishi R, Berg DK (1979) Survival and development of ciliary ganglion neurones grown alone in cell culture. Nature 277:232-234.

Nishi R, Berg DK (1981) Two components from eye tissue that differentially stimulate the growth and development of ciliary ganglion neurons in cell culture. J Neurosci 1:505-513.

Ordronneau P, Lindstrom PBM, Petrusz P (1981) Four unlabeled antibody bridge techniques: a comparison. J Histochem Cytochem 29:1397-1404

Patterson PH, Chun LY (1977) The induction of acetylcholine synthesis in primary cultures of dissociated rat sympathetic neurons. I. Effects of conditioned medium. Dev Biol 56:263-280.

Pilar G, Landmesser L, Burnstein L (1980) Competition for survival among developing ciliary ganglion cells. J Neurophysiol 43:233-254

Potter DD, Landis SC, Matsumoto SG, Furshpan EJ (1986) Synaptic functions in rat sympathetic neurons in microcultures. II. Adrenergic/ cholinergic dual status and plasticity. J Neurosci 6:1080-1090.

Role LW, Matossian VR, O'Brien RJ, Fischbach GD (1985) On the mechanism of acetylcholine receptor accumulation at newly formed synapses on chick myotubes. J Neurosci 5:2197-2204.

Schotzinger RJ, Landis SC (1988) Cholinergic phenotype developed by noradrenergic sympathelic neurons after innervation of a novel cholinergic target tissue in vivo. Nature 335:637-639.

Skalli O, Ropraz P, Trzeciak A, Benzonana G, Gillessen D, Gabbiani $G$ (1986) A monoclonal antibody against $\alpha$-smooth muscle actin: a new probe for smooth muscle differentiation. J Cell Biol 103:27872796.

Stevens LM, Landis SC (1987) Development and properties of the secretory response in rat sweat glands: relationship to the induction of cholinergic function in sweat gland innervation. Dev Biol 123:179190.

Stevens LM, Landis SC (1990) Target influences on transmitter choice by sympathetic neurons developing in the anterior chamber of the eye. Dev Biol 137:109-124.

Stöckli KA, Lottspeich F, Sendtner M, Masiakowski P, Carroll P, Gotz R, Lindholm D, Thoenen H (1989) Molecular cloning, expression, and regional distribution of rat ciliary neurotrophic factor. Nature 342: 920-923.

Tuttle JB, Suszkiw J, Ard M (1980) Long term survival and development of dissociated parasympathetic neurons in cell culture. Brain Res 183:161-180.

Tuttle JB, Vaca K, Pilar G (1983) Target influences on ${ }^{3} \mathrm{H} \mathrm{ACH}$ synthesis and release by ciliary ganglion neurons in vitro. Dev Biol 97 : 255-263.

Vacca LL, Abrahams SJ, Naftchi NE (1980) A modified peroxidase antiperoxidase procedure for improved localization of tissue antigens: localization of substance $P$ in rat spinal cord. J Histochem Cytochem 28:297-307.

Wong V, Kessler JA (1987) Solubilization of a membrane factor that stimulates levels of substance $P$ and choline acetyltransferase in sympathetic neurons. Proc Natl Acad Sci USA 84:8726-8729.

Yamamori T, Fukada K, Abersold R, Korsching S, Fann MJ, Patterson $\mathrm{PH}$ ( I 989) The cholinergic neuronal differentiation factor from heart cells is identical to leukemia inhibitory factor. Science 246:14121415.

Yodlowski ML, Fredieu JR, Landis SC (1984) Neonatal 6-hydroxydopamine treatment eliminates cholinergic sympathetic innervation and induces sensory sprouting in rat sweat glands. J Neurosci 4:15351548.

Zurn AD, Do KQ (1988) Purine metabolite inosine is an adrenergic neurotrophic substance for cultured chicken sympathetic neurons. Proc Natl Acad Sci USA 85:8301-8305. 